\title{
Asymptomatic hyperglycaemia is associated with increased intimal plus medial thickness of the carotid artery
}

\author{
Y. Yamasaki ${ }^{1}$, R. Kawamori ${ }^{2}$, H.Matsushima ${ }^{1}$, H.Nishizawa ${ }^{1}$, M.Kodama ${ }^{1}$, M. Kubota ${ }^{1}$, Y. Kajimoto ${ }^{1}$ T. Kamada $^{1}$ \\ ${ }^{1}$ First Department of Medicine, Osaka University School of Medicine, Osaka, Japan \\ ${ }^{2}$ Department of Medicine, Metabolism and Endocrinology, Juntendo University School of Medicine, Tokyo, Japan
}

Summary Atherosclerotic changes have not been demonstrated directly in asymptomatic hyperglycaemic non-diabetic subjects, although high mortality due to coronary heart disease has been reported. We measured arterial wall thickness non-invasively, in order to directly demonstrate atherosclerosis of the carotid arteries of hyperglycaemic non-diabetic subjects and to evaluate its risk factors.

The thicknesses of the intimal plus medial complex (IMT) of the carotid arteries of 112 asymptomatic hyperglycaemic non-diabetic subjects (aged 22-81, 95 males and 17 females) were compared with those of 55 healthy male subjects and 211 non-insulin-dependent NIDDM male diabetic patients. The subjects were subgrouped into impaired glucose-tolerant (IGT) subjects who had a 2-h glycaemic level of more than $7.8 \mathrm{mmol} / 1$, and non-IGT subjects whose 2-h glycaemic levels were within $6.7-7.7 \mathrm{mmol} / \mathrm{l}$.

Non-IGT and IGT subjects showed significantly greater IMTs than age-matched healthy males and showed no significant differences compared to agematched NIDDM patients. Multivariate analysis demonstrated that the risk factors for IMT of nonIGT and IGT subjects were age and systolic blood pressure. According to data on the accumulation of atherogenic risks (hypertension, dyslipidaemia, and smoking), IMT increased linearly in non-IGT and IGT subjects. However, non-IGT and IGT subjects without hyperlipidaemia, hypertension, or smoking risk still had significantly greater IMT than agematched normal males $(1.019 \pm 0.063$ vs $0.770 \pm$ $0.111 \mathrm{~mm}, p<0.05)$. Prevalence of ECG-indicated coronary heart disease was significantly higher in hyperglycaemic non-diabetic subjects and NIDDM with increased carotid arterial wall thickness (IMT $\geq 1.1 \mathrm{~mm}$ ) than in those without increased thickness $(\mathrm{IMT}<1.1 \mathrm{~mm})$. Asymptomatic hyperglycaemic non-diabetic subjects have increased thickness of their carotid arteries compared to age-matched male NIDDM patients. As one of several independent risk factors, mild hyperglycaemia advances atherosclerosis, which leads to coronary heart disease. [Diabetologia (1995) 38: 585-591]

Key words Atherosclerosis, borderline diabetes, im: paired glucose tolerance, non-insulin-dependent diabetes mellitus, B-mode, ultrasound, carotid artery, coronary heart disease, ECG.
Received: 5 August 1994 and in revised form: 12October 1994

Corresponding author: Dr. Y. Yamasaki, First Department of Medicine, Osaka University School of Medicine, Yamadaoka 2-2, Suita City, Osaka 565, Japan

Abbreviations: IMT, Intimal plus medial complex; NIDDM, non-insulin-dependent diabetes mellitus; IGT, impaired glucose tolerance; CHD, coronary heart disease; T-Chol, serum total cholesterol; HDL-C, high-density lipoprotein cholesterol; TG, serum triglycerides.
Several prospective studies [1-12] have suggested the occurrence of advanced atherosclerosis in coronary arteries and cerebral arteries in subjects with elevated blood glucose concentrations. In the Whitehall study $[1,2]$, stroke mortality and coronary heart disease (CHD) mortality were increased approximately twofold for subjects with impaired glucose tolerance (IGT), defined as a blood-glucose level above $5.3 \mathrm{mmol} / 1$. Also, the Bedford survey indicated that age-corrected CHD-mortality rates were higher for borderline diabetic patients than control subjects [3]. 
Table 1. Patient characteristics

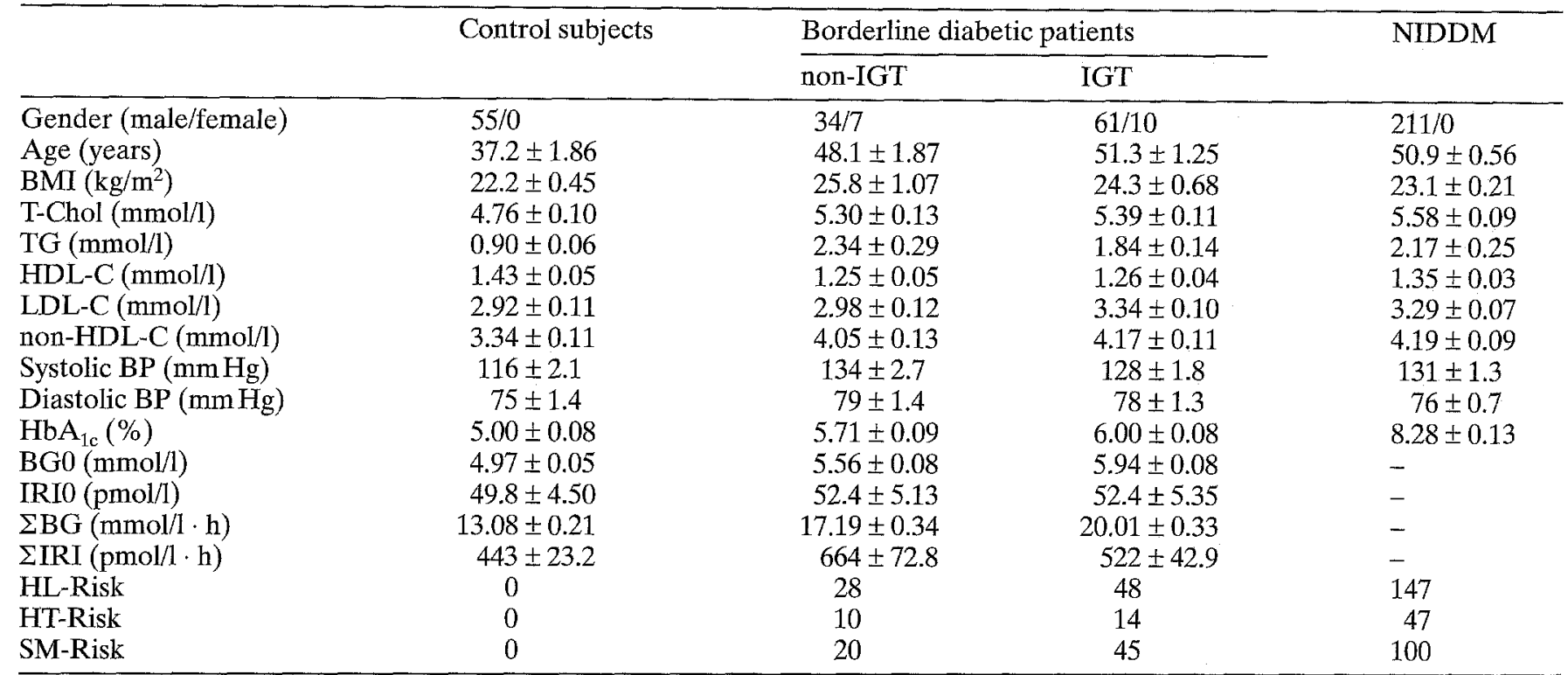

Mean \pm SEM.

HDL-C, HDL cholesterol; LDL-C, LDL cholesterol; BG0, pre-stimulated blood glucose; IRI0, pre-stimulated plasma insulin; $\Sigma$ PG, area under plasma glucose concentration curve after 75 -g OGTT; $\Sigma$ IRI, area under plasma insulin concentration curve after $75-\mathrm{g}$ OGTT.

The Paris prospective study [4-7] pointed out that the annual CHD mortality rates were increased almost twofold in subjects with IGT compared with those in normoglycaemic subjects. However, although symptomatic subjects have been examined by invasive coronary angiography $[13,14]$, information on asymptomatic atherosclerosis in asymptomatic hyperglycaemia is scarce.

Now this can be done using high resolution Bmode imaging of the carotid artery [15-22], which enables direct and non-invasive in vivo monitoring of carotid atherosclerosis even in subjects as young as 7 years old [22]. Because of its high-distance resolution, we were able to demonstrate, for the first time, a high prevalence of increased thickness of the carotid arteries in asymptomatic hyperglycaemic non-diabetic subjects. Predictors of carotid atherosclerosis in these subjects were analysed.

\section{Subjects, materials and methods}

Assessment of atherosclerosis. Ultrasonographic scanning of the carotid arteries was performed using an echotomographic system (EUB-450, Hitachi Medico, Tokyo, Japan) with an electrical linear transducer (midfrequency of $7.5 \mathrm{MHz}$ ). The axial resolution of this system was at least $0.3 \mathrm{~mm}$. Scanning of the extracranial carotid arteries in the neck was performed bilaterally in three different (i. e. anterior-oblique, lateral, and posterior-oblique) longitudinal projections as well as the transverse projection, as reported in our previous papers [20-22]. All the
HL-Risk, number of subjects with either T-Chol $>5.69 \mathrm{mmol} / \mathrm{l}$, $\mathrm{TG}>1.70 \mathrm{mmol} / \mathrm{l}$, HDL-C $<1.03 \mathrm{mmol} / 1$ or taking hypolipidaemic drugs. HT-Risk, number of subjects with either systolic blood pressure $>160$, diastolic blood pressure $>95 \mathrm{~mm} \mathrm{Hg}$, or taking anti-hypertensive drugs. SM-Risk, number of subjects who smoke more than one pack of cigarettes per day for 20 years

images were photographed. The scan lasted for an average of 30 min.

The intimal plus medial thickness defined by Pignoli et al. $[15,16]$ was measured as the distance from the leading edge of the first echogenic line to the leading edge of the second echogenic line. At each longitudinal projection, the site of the greatest thickness was sought along the arterial walls which are nearest the skin and farthest from the skin through the common carotid artery to the internal carotid artery. Three determinations of intimal plus medial thickness were conducted at the site of the greatest thickness and at two points, $1 \mathrm{~cm}$ upstream and $1 \mathrm{~cm}$ downstream from the site of the greatest thickness. These three determinations were averaged. The greatest value among the six averaged intimal plus medial thicknesses (three from the left and three from the right) was used as the representative value (IMT) for each individual. All scans were conducted by physicians (H.M. and H.N.) who were unaware of the clinical characteristics of the studied subjects. Determination of IMT on the photograph was performed by a physician (M.K.). The reproducibility of the IMT measurement was examined by conducting another scan 1 week later on eight participants. The mean difference in IMT between these two determinations was $0.01 \mathrm{~mm}$, and the standard deviation was $0.04 \mathrm{~mm}$, demonstrating good reproducibility for repeated measurements, as described previously $[15,16,21,22]$.

Patients. A total of 112 hyperglycaemic non-diabetic subjects aged 22-81 (95 males and 17 females), were recruited from among office workers, who were diagnosed as having glucose intolerance after oral glucose load (2-h plasma glucose $\geq 6.7 \mathrm{mmol} / \mathrm{l})$. The $75 \mathrm{~g}$ oral glucose load was administered a second time to selected subjects with impaired glucose tolerance (IGT; 2-h plasma glucose $\geq 7.8 \mathrm{mmol} / \mathrm{l}$ ) according to World Health Organisation criteria [23] or hyperglycaemic 


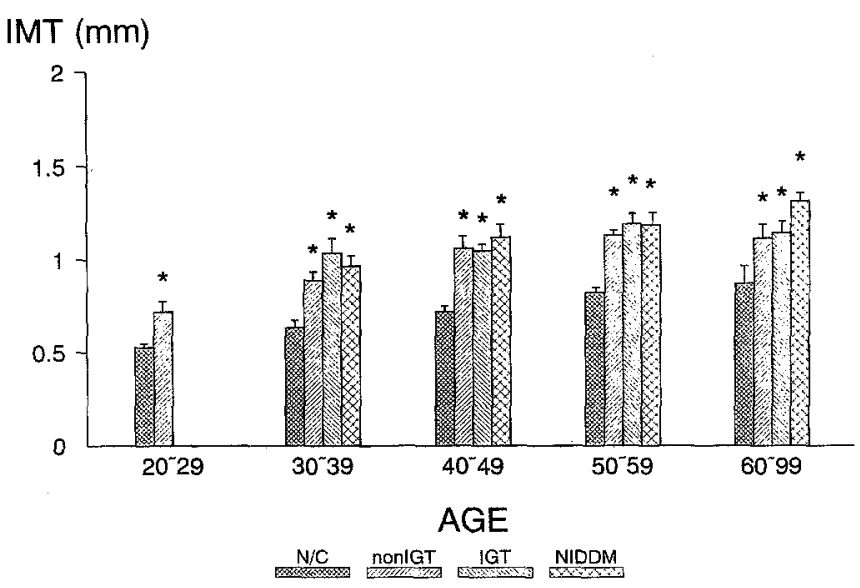

Fig. 1. Thickness of intimal plus medial complex (IMT, mean \pm SEM) of the carotid arteries in normal subjects, non-IGT subjects, IGT subjects, and NIDDM patients. Asterisks indicate significant differences from normal subjects $(* p<0.05)$ from $20-29$ years to 60 years and older

non-IGT subjects (non-IGT; $7.8 \mathrm{mmol} / \mathrm{l}>2$-h plasma glucose $\geq 6.7 \mathrm{mmol} / \mathrm{l}$, or 1 -h plasma glucose $>8.9 \mathrm{mmol} / \mathrm{l}$ and 2 - $\mathrm{h}$ plasma glucose $<6.7 \mathrm{mmol} / \mathrm{l}$ ) according to the criteria of the Japanese Diabetes Association [24]. Careful examination of medical histories showed that these subjects were free of symptoms due to CHD, cerebrovascular diseases and peripheral vascular diseases. Blood was drawn for analyses of serum total cholesterol (T-Chol) and HDL-cholesterol (HDL-C), serum triglycerides (TG) and haemoglobin $\mathrm{A}_{1 c}$ levels before the oral glucose load; blood was also drawn at 30, 60,90 and $120 \mathrm{~min}$ for analyses of plasma glucose and insulin concentrations. T-Chol, HDL-C, TG, plasma glucose, plasma insulin concentration and haemoglobin $A_{1 c}$ level were determined by standard laboratory techniques. The characteristics of the subjects are described in Table 1.

Two hundred and sixteen male non-insulin-dependent (NIDDM) patients aged 30-86 years were recruited from among outpatients of Osaka University Hospital. The definition of NIDDM was based on World Health Organisation criteria. Each patient who fulfilled the following inclusion criteria was considered for the study: 1) no episodes of ketoacidosis and absence of ketonuria; 2) diagnosis of diabetes after 30 years of age; 3 ) insulin therapy (if any) started after at least 5 years of known disease; 4) body mass index less than $30 \mathrm{~kg} /$ $\left.\mathrm{m}^{2} ; 5\right)$ absence of overt diabetic nephropathy or other renal tract disease and 6) no evidence of cardiac failure.

Fifty-five hospital male employees or non-diabetic healthy males aged 25-76 years attending Osaka University Hospital without hyperlipidaemia, hypertension, cardiovascular disease, cerebrovascular disease, or peripheral vascular disease served as control subjects. Normal blood glucose levels in these subjects were assessed with the 75-g oral glucose tolerance test according to the criteria of the Japanese Diabetes Association.

Life-long exposure to smoking (pack-years) was estimated as the product of years of smoking and the mean number of cigarettes smoked daily at the time of examination. Blood pressure was measured with a mercury sphygmomanometer. After $5 \mathrm{~min}$ rest in the supine position, three measurements were made in the sitting position and the means of these determinations were used in the present study. Low density lipoprotein cholesterol (LDL-C) was estimated by the Friedewald equation [25]. Non-HDL-cholesterol (non-HDL-C) was calculated as follows (non-HDL-C $=$ T-Chol-HDL-C).
The subjects were considered to be hypertensive $(n=17)$ if they were taking antihypertensive agents, and/or if systolic blood pressure was greater than $160 \mathrm{~mm} \mathrm{Hg}$, and/or if diastolic blood pressure was greater than $95 \mathrm{~mm} \mathrm{Hg}$. Dyslipidaemia was considered to be present for subjects $(n=60)$ taking hypolipidaemic drugs and/or if the serum cholesterol level was greater than $5.69 \mathrm{mmol} / 1$, if the TG level was greater than $1.70 \mathrm{mmol} / \mathrm{l}$, or if HDL cholesterol was less than $1.03 \mathrm{mmol} / 1$. Subjects were considered to have a smoking habit $(n=40)$ if patients had smoked for more than 20 pack-years. Body mass index (BMI) of the subjects studied was less than $30 \mathrm{~kg} / \mathrm{m}^{2}$.

A resting 12-lead ECG was done for all the subjects. The double Master two-step test was done for the subjects (24 non-IGT and IGT, 65 diabetic patients) who showed abnormal resting ECG. In this study $\mathrm{CHD}$ was diagnosed if a subject showed the following ECG findings: 1) major Q-QS changes [26], 2) a positive double Master two-step test [27].

\section{Statistical analysis}

Data are presented as mean \pm SEM. Values of IMT and clinical parameters among the study groups were compared by oneway ANOVA. Chi-square analysis was used to evaluate the significance of the prevalence rate of ECG-indicated CHD. Stepwise forward and backward multiple regression analysis was performed to account for the effects of different variables on IMT of non-IGT and IGT subjects who had not been given antihypertensive or hypolipidaemic drugs $(n=64)$. In this analysis, $F$ values for inclusion and exclusion of variables were set as 2.0. These statistical analyses were carried out using the HALBAU (Gendai Sugaku-sha, Kyoto, Japan) statistical package [28] on a personal computer (PC-9801 NS/R, NEC, Tokyo, Japan). Statistical significance was determined as $p$ less than 0.05 .

\section{Results}

Non-IGT subjects aged 22-29 years had significantly greater IMT than male control subjects aged 2529 years $(0.717 \pm 0.054$ vs $0.525 \pm 0.018 \mathrm{~mm}, p<0.01)$ (Fig.1). From $30-39$ years to 60 years and over, nonIGT and IGT subjects showed significantly greater IMTs than age-matched healthy males $(30-39$ years: $0.886 \pm 0.051,1.034 \pm 0.077,0.630 \pm 0.040 \mathrm{~mm} ; 40$ 49 years: $1.058 \pm 0.062,1.047 \pm 0.032,0.716 \pm 0.029$ $\mathrm{mm} ; 50-59$ years: $1.130 \pm 0.028,1.190 \pm 0.058,0.822 \pm$ $0.023 \mathrm{~mm}$; 60 years and over: $1.117 \pm 0.081,1.145 \pm$ $0.063,0.870 \pm 0.091 \mathrm{~mm}$, respectively). IMTs of male control subjects were less than $1.1 \mathrm{~mm}$. Thus, the criteria of carotid atherosclerosis was set as the upper limit of IMT in the normal control subjects $(1.1 \mathrm{~mm})$ as previously described [21,22]. There were no significant differences in IMTs among non-IGT subjects, IGT subjects and NIDDM patients from 30-39 years to 60 years and more. Non-IGT subjects had significantly lower fasting plasma glucose, $\Sigma \mathrm{PG}$, and $\mathrm{HbA}_{1 \mathrm{c}}$ levels than IGT subjects. Non-IGT subjects showed higher (but not significantly) triglyceride levels $(2.34 \pm 0.29 \mathrm{mmol} / \mathrm{l})$ than IGT subjects $(1.84 \pm 0.14$ $\mathrm{mmol} / \mathrm{l})$. 


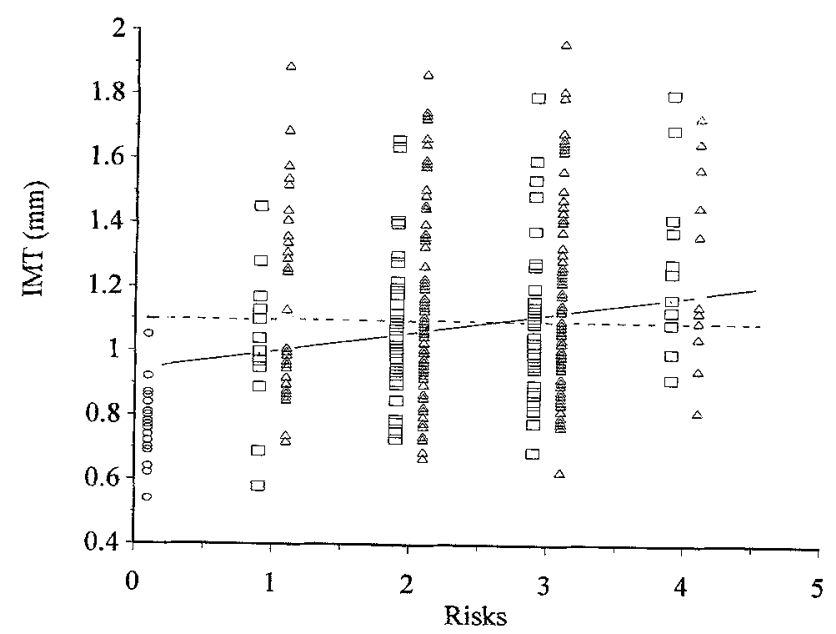

Fig. 2. Correlation between thickness of intimal plus medial complex (IMT) and accumulation of atherogenic risks, such as borderline diabetes, hypertension, dyslipidaemia, and smoking habit in normal males $(O)$, borderline diabetic patients $(\square)$ and male NIDDM subjects $(\triangle)$. The solid line indicates a linear regression line between IMTs and risks in borderline diabetic patients $(\mathrm{IMT}=0.0615 \times$ risk $+0.926, r=0.215, p=0.0236$ ). The broken line indicates the upper limit of IMT in normal subjects (IMT $=1.1 \mathrm{~mm}$ )

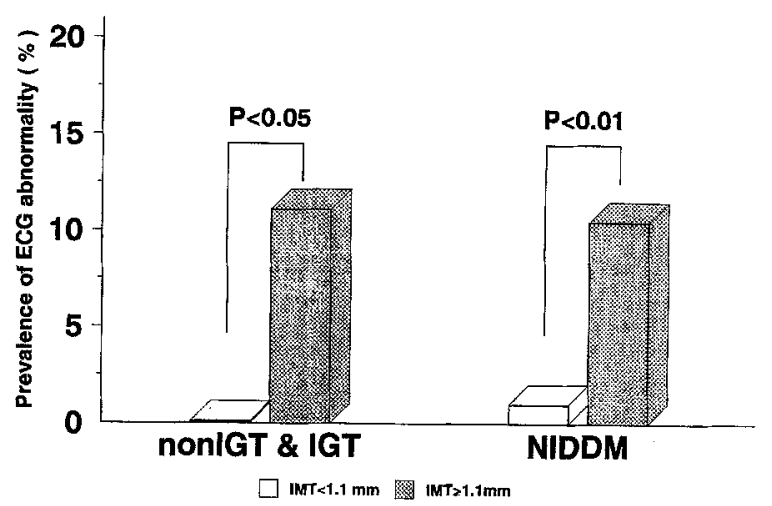

Fig.3. Prevalence rate of ECG-indicated coronary heart disease of hyperglycaemic non-diabetic patients and NIDDM patients without (IMT $<1.1 \mathrm{~mm}$ ) and with carotid atherosclerosis $(\mathrm{IMT} \geq 1.1 \mathrm{~mm})$

Stepwise multiple variate analysis (Table 2) demonstrated that the risk factors in IMT of both nonIGT and IGT subjects were age, systolic blood pressure, pack-years of smoking and fasting blood glucose $\left(r^{2}=0.344\right)$, when the $F$ value for inclusion was set as 2. However, the pack-years of smoking and fasting blood glucose did not reach statistical significance.

The hyperglycaemic non-diabetic patients without other risk factors (risk 1) $(n=13$, age $49.4 \pm 3.7$ years) had a significantly higher IMT than agematched male control subjects $(n=23$, age $49.8 \pm 1.9$ years) $(1.019 \pm 0.063$ vs $0.770 \pm 0.015 \mathrm{~mm}, p<0.05)$. They had clinical characteristics and insulin response to $75 \mathrm{~g}$ OGTT (T-Chol; $5.00 \pm 0.13 \mathrm{mmol} / \mathrm{l}$, TG;
$0.97 \pm 0.13 \mathrm{mmol} / \mathrm{l}, \quad$ HDL-C; $1.62 \pm 0.12 \mathrm{mmol} / \mathrm{l}$, LDL-C; $3.13 \pm 0.14 \mathrm{mmol} / 1$, non-HDL-C; $3.54 \pm 0.12$ $\mathrm{mmol} / \mathrm{l}$, systolic BP; $129 \pm 4.4 \mathrm{~mm} \mathrm{Hg}$, diastolic BP; $77 \pm 2.6 \mathrm{~mm} \mathrm{Hg}, \Sigma$ immunoreactive insulin; $409 \pm$ $80.4 \mathrm{mmol} / \mathrm{l}$ ) compared to normal males, but had a significantly higher $\Sigma B G(17.4 \pm 0.76)$. According to accumulation of risk factors, IMT linearly increased to $1.286 \pm 0.067 \mathrm{~mm}$ in hypertensive, hyperlipidaemic hyperglycaemic non-diabetic subjects with a smoking risk (risk 4) $(\mathrm{IMT}=0.06152 \times$ risks + $0.926, r=0.226, p=0.0236$; Fig. 2). The hyperglycaemic non-diabetic subjects whose IMTs were more than $1.1 \mathrm{~mm}$ showed a significantly higher prevalence rate of ECG-indicated CHD than those without carotid atherosclerosis (IMT $<1.1 \mathrm{~mm})(11.1 \mathrm{vs}$ $0.0 \%$, Fig. 3). The NIDDM patients whose IMTs were more than $1.1 \mathrm{~mm}$ showed a significantly higher prevalence of ECG abnormality than those without carotid atherosclerosis (IMT < $1.1 \mathrm{~mm}$ ) (10.5 vs $1.0 \%$ ). Half (2 of 4 ) of the subjects with obesity (BMI $>25.0 \%$ ), high triglyceride level $(>1.70 \mathrm{mmol} /$ l), low HDL cholesterol level $(<1.03 \mathrm{mmol} / \mathrm{l})$, and hypertensive risk showed a history of asymptomatic myocardial infarction.

\section{Discussion}

A series of studies $[15,16]$ has indicated that the IMT determined by B-mode imaging is comparable to the thickness of the IMT measured by pathological and histological examinations. Pignoli et al. [16] showed the highly linear relationship of the IMT measured by $\mathrm{B}$-mode imaging with the thickness of intimal plus medial complexes determined by histological examination of subjects $20-25$ years old, who were found to have IMT of $0.5 \mathrm{~mm}$. The echotomographic system with an electrical linear transducer (midfrequency of $7.5 \mathrm{MHz}$ ) employed in the present study has an axial resolution of $0.3 \mathrm{~mm}$. In this study, we used this method to determine early atherosclerosis in subjects with elevated blood glucose concentrations indicative of glucose intolerance but below those diagnostic of diabetes mellitus.

In this study, asymptomatic hyperglycaemic subjects were recruited from office workers who were given annual examinations of fasting plasma glucose, several lipid profiles, blood pressure levels, and urine samples. When the fasting plasma glucose level was over $6.1 \mathrm{mmol} / 1$ or urine tested positive for glucose, they were given a $75-\mathrm{g}$ oral glucose tolerance test. The subjects were mostly male and their carotid IMTs were compared with those of normal males and NIDDM males.

Non-IGT and IGT subjects showed significantly greater IMTs than male control subjects from $30-$ 39 years to 60 years of age and over. Non-IGT subjects aged 22-29 years had IMTs $0.192 \mathrm{~mm}$ greater 
Table 2. Multivariate regression analysis on borderline diabetic subjects

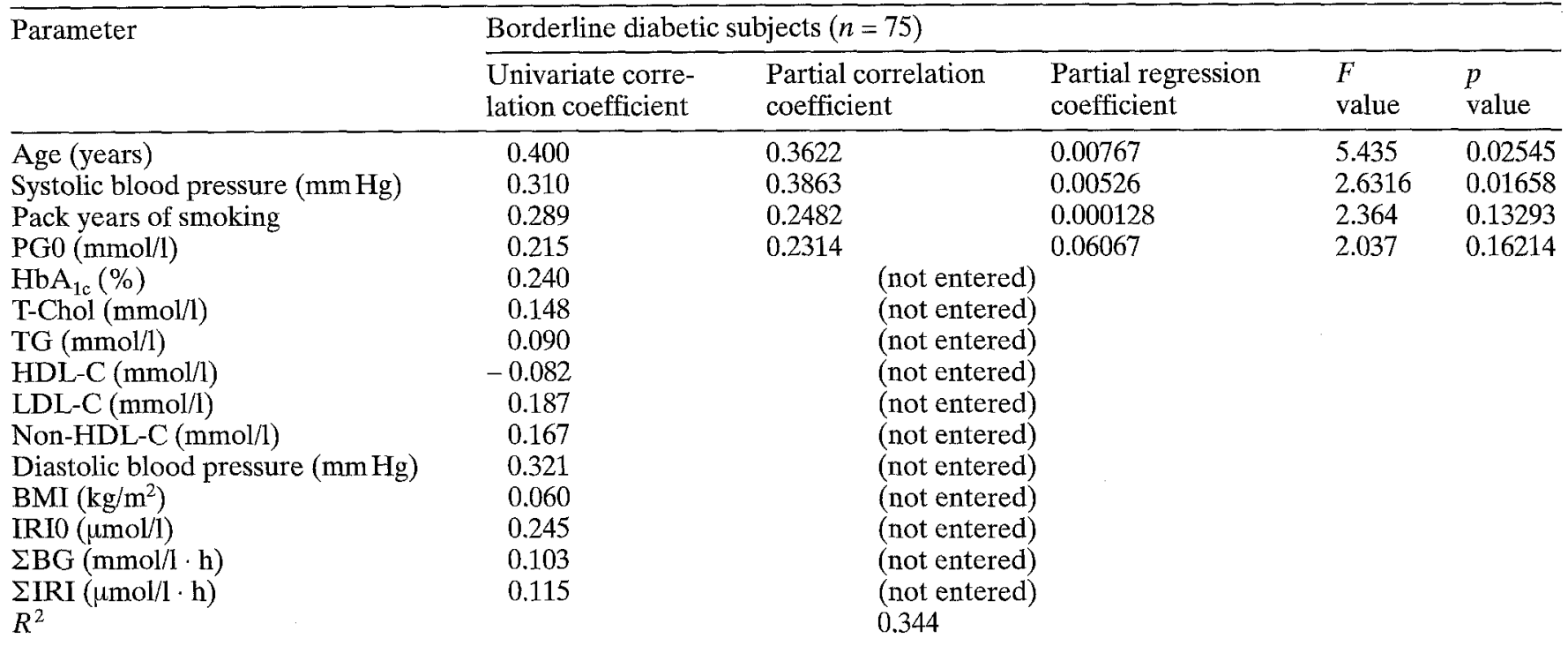

PG0, pre-stimulated plasma glucose concentration; IRI0, prestimulated plasma insulin concentration; $\Sigma \mathrm{BG}$, area under curve of plasma glucose concentration after $75-\mathrm{g}$ oral glucose tolerance test; $\Sigma$ IRI, area under curve of plasma insulin concentration after 75-g oral glucose tolerance test

than age-matched male control subjects. By considering the detection limit $(0.3 \mathrm{~mm})$ and discrimination limit of this method $(0.1 \mathrm{~mm})$, these data indicate the progression of atherosclerosis in carotid arteries of young hyperglycaemic non-diabetic patients.

There were no significant differences in IMTs among non-IGT subjects, IGT subjects and NIDDM patients from 30-39 years to 60 years and over. These data were comparable to the Bedford survey [3] in which male borderline diabetic patients were found to have CHD mortality compatible with that of male diabetic patients.

In this study, for example, borderline diabetic patients of 40-49 years old showed increased thickness of their carotid arterial wall of $1.06 \mathrm{~mm}$. This value is greater than IMT $(0.67 \mathrm{~mm})$ of hyperlipidaemic patients ( $46 \pm 6.0$ years old) reported by Poli et al. [17]. These data showed a possibility that borderline diabetic patients have greater thickness of the carotid artery than hyperlipidaemic patients.

Stepwise multiple variate analysis demonstrated that the risk factors for IMT of non-IGT and IGT subjects as a group were age and systolic blood pressure. The pack-years of smoking and the fasting plasma glucose level were related to IMT ( $F$ values $>2.0$ ) but were not significant independent predictors of IMT of hyperglycaemic subjects (Table 2). Among these risk factors, the significance of systolic blood pressure and smoking was pointed out by the Whitehall study $[1,2]$ and the Bedford survey [3]. Higher plasma insulin level was found to be a risk factor in the Paris study [4-7] and the Helsinki Policemen study [8]. In the Paris study, the plasma triglyceride
Stepwise multivariant regression analysis was done on 75 borderline diabetic patients to whom no medication had been given. Sex: men $=1$, women $=0$. Pack years of smoking was estimated as the product of years of smoking and the mean number of packs smoked daily.

level was the only factor positively and significantly associated with coronary death [6]. The Honolulu Heart Program indicated that post-challenge hyperglycaemia was an independent risk factor of $\mathrm{CHD}$ $[11,12]$. Significant association of hyperlipidaemia and hypertension noted in subjects with IGT [29] suggested that the discrepancy of risk factors between the present study and the prospective studies might be due to differences in race or study design.

IMT was linearly related to the accumulation of atherogenic risks, such as hyperglycaemia, hypertension, hyperlipidaemia or smoking habit. We have already shown that although IMT increased with age, it never exceeded $1.1 \mathrm{~mm}$ in normal individuals [21]. This value is comparable to that mentioned previously [16]. Therefore, we adopted $1.1 \mathrm{~mm}$ as a cutoff value to determine the existence of carotid atherosclerosis. All subjects except two with these four risk factors showed advanced carotid atherosclerosis (IMT $\geq 1.1 \mathrm{~mm}$ ). These data indicate that such risks might cause additive rather than synergistic progression of atherosclerosis, as reported for diabetic and non-diabetic subjects [30].

The hyperglycaemic subjects without other risk factors still showed significantly advanced carotid atherosclerosis. This implies that 'mild hyperglycaemia' can cause progression of atherosclerosis. Several possible mechanisms were proposed by which hyperglycaemia may cause atherosclerosis. Increased glycation of circulation lipoproteins observed in diabetes [31] reduces their binding to the LDL receptor [32]. Also, glycated HDL is cleared from plasma at an enhanced rate [33] and its ability to stimulate chol- 
esterol efflux from arterial cells is diminished. Increased glycation of collagen, well-described in diabetic patients [34], stimulates platelet aggregation to a greater extent than does non-glycated collagen [35]. Recently, advanced glycation endproduct proteins have been shown to induce the transendothelial migration of monocytes and the subsequent expression of platelet-derived growth factor by macrophages [36].

The hyperglycaemic non-diabetic patients we studied showed a high prevalence of hyperlipidaemia (76 of 112) and hypertension (24 of 112). A high prevalence of these abnormalities has also been reported by Laakso and Barrett-Connor [29]. These abnormalities have been suggested to result from insulin resistance or hyperinsulinaemia $[37,38]$ which may lead to a high $\mathrm{CHD}$ mortality rate, termed syndrome $\mathrm{X}$ [39] or the deadly quartet [40]. Another possibility, suggested by Laakso et al. [41], is that insulin resistance rather than hyperinsulinaemia causes the progression of atherosclerosis.

IMT is a clinically useful quantitative index of carotid atherosclerosis as suggested by several investigators [15-22]. The atherosclerotic processes occurring in the coronary arteries, extracranial carotid arteries, and peripheral arteries in the legs appear to be pathologically identical [42]. Also, a correlation between coronary and carotid atherosclerosis has been noted in previous autopsy studies $[43,44]$. The present study clearly demonstrates that asymptomatic hyperglycaemic non-diabetic subjects had increased carotid arterial wall thickness, comparable to that of agematched diabetic patients. The high prevalence of ECG-indicated CHD in hyperglycaemic non-diabetic subjects and NIDDM males with increased thickness of carotid arterial wall indicates that a high CHD mortality rate can be anticipated in these subjects.

The present study showed that B-mode imaging of carotid arteries could reveal increased thickness of the carotid arterial wall in asymptomatic hyperglycaemic non-diabetic subjects even as young as aged 22-29 years. Impaired glucose tolerance, dyslipidaemia, hypertension, and smoking remain as additive risk factors for carotid atherosclerosis.

Acknowledgements. The study was supported by grants from the Daiwa Health Foundation and the Osaka Gas Health Foundation.

\section{References}

1. Fuller JH, Shipley MJ, Rose G, Jarrett RJ, Keen H (1980) Coronary-heart-disease risk and impaired glucose tolerance. The Whitehall Study. Lancet I: 1373-1376

2. Fuller JH, Shipley MJ, Rose G, Jarrett RJ, Keen H (1983) Mortality from coronary heart disease and stroke in relation to degree of glycemia: the Whitehall study. BMJ 287: $867-870$
3. Jarrett RJ, McCartney P, Keen H (1982) The Bedford survey: ten year mortality rates in newly diagnosed diabetics, borderline diabetics and normoglycemic controls and risk indices for coronary heart disease in borderline diabetics. Diabetologia 22: 79-84

4. Ducimetiere P, Eschwege E, Papoz L, Richard JL, Claude JR, Rosselin G (1980) Relationship of plasma insulin levels to the incidence of myocardial infarction and coronary heart disease mortality in a middle-aged population. Diabetologia 19: 205-210

5. Eschwege E, Richard JL, Thibult N et al. (1985) Coronary heart disease mortality in relation with diabetes, blood glucose and plasma insulin levels. The Paris prospective study, ten years later. Horm Metab Res 15 [Suppl]: 41-46

6. Fontbonne A, Eschwege E, Cambien F et al. (1989) Hypertriglyceridemia as a risk factor of coronary heart disease mortality in subjects with impaired glucose tolerance or diabetes. Results from 11-year follow-up of the Paris prospective study. Diabetologia 32: 300-304

7. Fontbonne A, Charles MA, Thibult $\mathrm{N}$ et al. (1991) Hyperinsulinemia as a predictor of coronary heart disease mortality in a healthy population: the Paris prospective study, 15-year follow-up. Diabetologia 34: 356-361

8. Pyorala K, Savolainen E, Sirkka K, Haapakoski J (1985) Plasma insulin as coronary heart disease risk factor: relationship to other risk factors and predictive value during $9 \frac{1}{2}$-year follow-up of the Helsinki Policemen study population. Acta Med Scand 701 [Suppl]: 38-52

9. Welborn TA, Wearne K (1979) Coronary heart disease incidence and cardiovascular mortality in Busselton with reference to glucose and insulin concentrations. Diabetes Care 2: $154-160$

10. Hargreaves AD, Logan RL, Elton RA, Buchanan KD, Oliver MF, Riemersman RA (1992) Glucose tolerance, plasma insulin, HDL cholesterol and obesity: 12-year follow-up and development of coronary heart disease in Edinburgh men. Atherosclerosis 94: 61-69

11. Donahue RP, Abbott RD, Reed DM, Yano K (1987) Postchallenge glucose concentration and coronary heart disease in men of Japanese ancestry. Honolulu Heart Program. Diabetes 36: 689-692

12. Yano K, Kagan A, McGee D, Phoads GG (1982) Glucose intolerance and nine-year mortality in Japanese men in Hawaii. Am J Med 72: 71-80

13. Yamamoto A, Yamamura T, Kawaguchi A, Kameda K, Matsuzawa Y (1991) Triglyceride and glucose intolerance as a risk factor for coronary heart disease. Cardiology 78: 185-193

14. Takeda Y, Mifune J, Taga K et al. (1991) Multiple risk factors in coronary artery disease patients with abnormal glucose tolerance. Jpn Heart J 32: 35-43

15. Pignoli P (1984) Ultrasound B-mode imaging for arterial wall thickness measurement. Atherosclerosis Review 12: 177-184

16. Pignoli P, Tremoli E, Poli A, Oreste P, Paoletti R (1986) Intimal plus medial thickness of the arterial wall: a direct measurement with ultrasound imaging. Circulation 74: 1399-1406

17. Poli A, Tremoli E, Colombo A, Sirtori M, Pignoli P, Paoletti R (1988) Ultrasonographic measurements of the common carotid artery wall thickness in hypercholesterolemic patients: a new model for the quantitation and followup of preclinical atherosclerosis in living human subjects. Atherosclerosis 70: 253-261

18. Salonen R, Seppanen K, Rauramaa R, Salonen JT (1988) Prevalence of carotid atherosclerosis and serum cholesterol levels in Eastern Finland. Arteriosclerosis 8: 788-792 
19. Salonen R, Salonen JT (1990) Progression of carotid atherosclerosis and its determinants. A population-based ultrasonography study. Atherosclerosis 81: 33-40

20. Handa N, Matsumoto M, Maeda H et al. (1990) Ultrasonic evaluation early carotid atherosclerosis. Stroke 21: 15671572

21. Kawamori R, Yamasaki Y, Matsushima H et al. (1992) Prevalence of carotid atherosclerosis in diabetic patients - Ultrasound high-resolution B-mode imaging on carotid arteries. Diabetes Care 15: 1290-1294

22. Yamasaki Y, Kawamori R, Matsushima H et al. (1994) Atherosclerosis in carotid artery of young IDDM monitored by ultrasound high resolution B-mode imaging. Diabetes 43: 634-639

23. WHO Expert Committee (1980) Second report on diabetes mellitus. Technical report series 646. Geneva, World Health Organization

24. Jpn Diabetes Association Committee (1982) Committee report on diagnosis of diabetes. J Jpn Diabetes Assoc 25: 859-866 (in Japanese)

25. Friedewald WT, Levy RI, Fredrickson DS (1972) Estimation of the concentration of low lipoprotein in plasma without the use of preparative ultracentrifuge. Clin Chem 18: 499

26. Prineas RJ, Crow RS, Blackburn H (1982) The Minnesota Code Manual of Electrocardiographic Findings. Standards and Procedures for Measurement and Classification. John Wright, Boston

27. Simanson E, Keys A (1956) Electrocardiographic exercise test: changes in scalar ECG and in mean spatial QRS and $T$ vectors in two types of exercise effect of absolute and relative body weight and comment on normal standards. Am Heart J 52: 83-105

28. Yanai H, Takai H (1989) Handbook of multivariate analysis. Kyoto, Gendai-Sugaku-sha, p 311 (in Japanese)

29. Laakso M, Barrett-Connor E (1989) Asymptomatic hyperglycemia is associated with lipid and lipoprotein changes favoring atherosclerosis. Arteriosclerosis 9: 665-672

30. Stamler J, Vaccaro O, Neaton JD, Wentworth D, MRFIT Research Group (1993) Diabetes, other risk factors, and 12-yr cardiovascular mortality for men screened in the multiple risk factor intervention trial. Diabetes Care 16: 434 443

31. Curtiss LK, Witztum JL (1985) Plasma apolipoproteins A-I, A-II, B, C-I and E are glycosylated in hyperglycemic diabetic subjects. Diabetes 34: 452-461
32. Witztum JL, Mahoney EM, Branks MJ et al. (1985) Nonenzymatic glucosylation of low-density lipoprotein alters its biologic activity. Diabetes 31: 283-291

33. Witztum JL, Fisher M, Pietro Tet al. (1982) Nonenzymatic glucosylation of high-density lipoproteins accelerates its catabolism in guinea pigs. Diabetes 31: 1029-1032

34. Monnier VM, Kohn RR, Cerami A (1984) Accelerated age-related browning of human collagen in diabetes mellitus. Proc Natl Acad Sci USA 81: 583-587

35. LePape A, Guitton JD, Gutman N et al. (1983) Nonenzymatic glycosylation of collagen in diabetes: incidence on increased normal platelet aggregation. Haemostasis 13: $36-41$

36. Kirstein M, Brett J, Rodoff S et al. (1990) Advanced protein glucosylation induces transendothelial human monocyte chemotaxis and secretion of platelet-derived growth factor: role in vascular disease of diabetes and aging. Proc Natl Acad Sci USA 87: 9010-9014

37. Zavaroni I, Bonora E, Pagliara M et al. (1989) Risk factors for coronary artery disease in healthy persons with hyperinsulinemia and normal glucose tolerance. New Engl J Med 320: 702-706

38. Laakso M, Sarlund H, Mykkanen L (1990) Insulin resistance is associated with lipid and lipoprotein abnormalities in subjects with varying degree of glucose tolerance. Arteriosclerosis 10: 223-231

39. Reaven G (1988) Role of insulin resistance in human disease. Diabetes 37: 1596-1607

40. Kaplan NM (1989) The deadly quartet. Upper-body obesity, glucose intolerance, hypertriglyceridemia, and hypertension. Arch Intern Med 149: 1514-1520

41. Laakso M, Sarlund H, Salonen R et al. (1991) Asymptomatic atherosclerosis and insulin resistance. Arteriosclerosis Throm 11: 1068-1076

42. McGill HC, Arias-Stella J, Carbonell LM, Correa P, de Veyra EA (1968) General findings of the International Atherosclerosis Project. Lab Invest 18: 498-502

43. Solberg LA, Strong JP (1983) Risk factors and atherosclerotic lesions: a review of autopsy studies. Arteriosclerosis $3: 187-198$

44. Holme I, Enger SC, Helgeland A et al. (1981) Risk factors and raised atherosclerotic lesions in coronary and cerebral arteries: statistical analysis from the Oslo Study. Arteriosclerosis 1: 25 